\title{
O papel do Tribunal de Justiça da União Europeia e dos tribunais nacionais num mundo globalizado
}

https://doi.org/10.21814/uminho.ed.30.4

\author{
Ana Sofia Carvalho \\ Juíza de Direito no Tribunal Administrativo e Fiscal do Porto \\ Isabel Restier Poças \\ Advogada
}

\section{Introdução}

A proteção jurídica dos cidadãos não se circunscreve aos limites das nossas fronteiras, sendo de destacar o facto da União Europeia apresentar um quadro adequado de proteção dos direitos da pessoa humana, dispondo das correspondentes instâncias judiciais, pois "a Ordem Jurídica da União Europeia não seria verdadeiramente eficaz se as suas normas não beneficiassem de uma sólida garantia jurisdicional. Ou seja, todos os seus destinatários (Estados e particulares) devem respeitar as normas da União." ${ }^{1}$.

A garantia jurisdicional do Direito da União Europeia foi deixada, a cargo, por um lado, dos tribunais nacionais em geral, dado que "são eles que, em primeira linha, aplicam um número considerável de normas e de atos da União constituídos por disposições diretamente aplicáveis ou que gozam de efeito direto nos litígios que eventualmente ocorram nas relações entre particulares (indivíduos ou empresas) ou entre particulares e os Estados-membros"2, e por outro lado, do Tribunal de Justiça da União Europeia (TJUE).

O TJUE tem por missão pugnar pela interpretação e aplicação uniforme do Direito da União pelos Estados-membros e velar pelo seu cumprimento. No âmbito dessas funções, ressaltam dois tipos de ações: o reenvio prejudicial e a ação por incumprimento.

1 MARTINS, Ana Maria Guerra - Manual de Direito da União Europeia, Coimbra: Almedina, 2014, p. 539.

2 Ibidem. 


\section{0 reenvio prejudicial}

Nos termos do artigo 267. ${ }^{\circ}$ do Tratado sobre o Funcionamento da União Europeia (TFUE), “[o] Tribunal de Justiça da União Europeia é competente para decidir, a título prejudicial:

a) Sobre a interpretação dos Tratados;

b) Sobre a validade e a interpretação dos atos adotados pelas instituições, órgãos ou organismos da União.

Sempre que uma questão desta natureza seja suscitada perante qualquer órgão jurisdicional de um dos Estados-Membros, esse órgão pode, se considerar que uma decisão sobre essa questão é necessária ao julgamento da causa, pedir ao Tribunal que sobre ela se pronuncie.

Sempre que uma questão desta natureza seja suscitada em processo pendente perante um órgão jurisdicional nacional cujas decisões não sejam suscetíveis de recurso judicial previsto no direito interno, esse órgão é obrigado a submeter a questão ao Tribunal.

Se uma questão desta natureza for suscitada em processo pendente perante um órgão jurisdicional nacional relativamente a uma pessoa que se encontre detida, o Tribunal pronunciar-se-á com a maior brevidade possível”.

Daqui resulta, conforme cedo se concluiu, que um Tribunal que decida em última instância deve submeter questões de interpretação do Direito da União Europeia, em caso de dúvida, ao Tribunal de Justiça, salvo se a questão for impertinente, se já houver jurisprudência sobre essa questão por parte do Tribunal ou se a questão for manifestamente clara e não suscite qualquer dúvida razoável ${ }^{3}$.

Neste sentido, caberá essencialmente aos Tribunais Superiores suscitar as questões prejudiciais que considerarem relevantes para a boa decisão da causa, sem prejuízo dos limites à obrigação de suscitar a questão prejudicial acima referidos.

O reenvio prejudicial está regulado nos artigos $93.0^{\circ}$ a $118 . .^{\circ}$ do Regulamento de Processo do Tribunal de Justiça ${ }^{4}$, sendo que os artigos $93 . .^{\circ}$ a $104 .^{\circ}$ contêm disposições gerais, os artigos $105 .^{\circ}$ e $106 .^{\circ}$ contêm a regulação da tramitação acelerada, os artigos $107 .^{\circ}$ a $114 .^{\circ}$ reportam-se à tramitação urgente e os artigos $115 .^{\circ}$ a $118 .^{\circ}$ à assistência judiciária 5 .

3 Neste sentido, ver sumário do acórdão do Supremo Tribunal Administrativo de 07.10.1998, in processo n. ${ }^{\circ}$ 022364, [consultado em 2021-04-09] disponível na World Wide Web: < www.dgsi.pt.>.

4 [Consultado em 2021-04-09]. Disponível na World Wide Web: <https://eur-lex.europa.eu/legal-content/PT/TXT/?uri=celex\%3A32012Q0929\%2801\%29>.

5 Nesta matéria ressalta-se a possibilidade de solicitar o benefício de assistência judiciária em qualquer momento quando uma parte no litígio no processo principal não tiver a possibilidade de fazer face, total ou parcialmente, às despesas do processo (cf. artigo $115 .{ }^{\circ}$ ). 
O artigo $94 .^{\circ}$ de tal Regulamento é de extrema importância porquanto estabelece o que o pedido de decisão prejudicial deve conter, pelo que o transcrevemos aqui:

"Para além do texto das questões submetidas ao Tribunal a título prejudicial, o pedido de decisão prejudicial deve conter:

a) uma exposição sumária do objeto do litígio bem como dos factos pertinentes, conforme apurados pelo órgão jurisdicional de reenvio, ou, no mínimo, uma exposição dos dados factuais em que as questões assentam;

b) o teor das disposições nacionais suscetíveis de se aplicar no caso concreto e, sendo caso disso, a jurisprudência nacional pertinente;

c) a exposição das razões que conduziram o órgão jurisdicional de reenvio a interrogar-se sobre a interpretação ou a validade de certas disposições do direito da União, bem como o nexo que esse órgão estabelece entre essas disposições e a legislação nacional aplicável ao litígio no processo principal."

«O reenvio é, assim, a explicitação do princípio de cooperação a que alude o Tratado. Este é um incidente de instância que se desenvolve a nível nacional. A instância suspende-se e coloca-se a questão ao TJUE. A decisão do TJUE é obrigatória erga omnes.

O reenvio é um procedimento de juiz a juiz. O acórdão Ferma Shwartze de 1.12.1965 disse sobre este procedimento: “O reenvio é um instrumento de cooperação judiciária pelo qual um juiz nacional e o juiz comunitário são chamados a contribuir para uma decisão que assegure a aplicação uniforme do direito comunitário no seio dos Estados-Membros"» ${ }^{6}$.

Um destaque atual desta cooperação é a possibilidade prevista no artigo $104 .^{\circ}$, n. $^{\circ} 2$ do Regulamento de Processo do Tribunal de Justiça de os órgãos jurisdicionais nacionais poderem recorrer novamente ao Tribunal de Justiça quando considerem que não estão suficientemente esclarecidos pela decisão prejudicial do Tribunal.

No domínio fiscal, o reenvio prejudicial tem especial importância no âmbito dos direitos aduaneiros, em virtude do Código Aduaneiro da União e dos regulamentos relativos aos direitos antidumping e compensadores, bem como no âmbito do Imposto sobre o Valor Acrescentado (IVA). Veja-se a título exemplificativo o recente acórdão do Tribunal de Justiça da União Europeia de 3/3/2021, proferido no processo C-7/207, no qual o Tribunal concluiu que "O artigo $71 .^{\circ}, \mathrm{n} .^{\circ} 1$, segundo parágrafo, da Diretiva 2006/112/CE do Conselho, de 28 de novembro de 2006, relativa ao sistema comum do imposto sobre o valor acrescentado, deve ser interpretado no sentido de que o imposto sobre o valor acrescentado na importação relativo a bens sujeitos a direitos aduaneiros se constitui no Estado-Membro onde foi constatada a inobservância

6 CARVALHO, José Maria da Fonseca - Do reenvio prejudicial, in TEIXEIRA, Glória (Dir.) - "Il Congresso de Direito Fiscal", Porto: Vida Económica". 2012, ISBN 978-972-788-524-4, p. 173.

7 [Consultado em 2021-04-09], Disponível na World Wide Web: <https://curia.europa.eu/juris/document/document.jsf?text=\&docid=238443 \& pageIndex=0\&doclang=pt \&mode=req \&dir=\&occ=first \&part $=1 \&$ cid $=5661723>$. 
de uma obrigação imposta pela legislação aduaneira da União, quando os bens em causa, mesmo que tenham sido fisicamente introduzidos no território aduaneiro da União noutro Estado-Membro, tenham entrado no circuito económico da União no Estado-Membro onde foi feita a referida constatação".

Como vemos, o reenvio prejudicial desempenhou e desempenha um papel fundamental no desenvolvimento do Direito da União, contribuindo para a sua evolução, tendo a maior parte das grandes inovações jurisprudenciais ocorrido com base em processos nele baseados e constitui uma esperança de aplicação correta do Direito da União para os particulares ${ }^{8}$.

\section{A ação por incumprimento}

A ação por incumprimento encontra-se prevista nos artigos $258 .^{\circ}$ a $260 .^{\circ}$ do TFUE. A necessidade do respeito pelo direito da União Europeia justifica a existência deste mecanismo que decorre do artigo $4 .^{\circ}$, n. $^{\circ} 3$, do Tratado da União Europeia, no sentido de que ["os Estados membros se obrigam a tudo fazer para realizar os objectivos da União expressos nos tratados, obrigação de lealdade que tem tanto uma dimensão positiva ("Os Estados membros tomam todas as medidas ...") como uma dimensão negativa ("os Estados membros...abstêm-se de qualquer medida...")]?

Por vezes, quando tal seja considerado útil pela Comissão, antes da ação por incumprimento, há lugar à intervenção de um sistema mais informal - "EU Pilot" - mecanismo com base num diálogo informal entre a Comissão e o Estado-Membro em causa, acerca de questões relacionadas com um potencial incumprimento da legislação da UE. - cf. Comunicação “Legislação da UE: Melhores resultados através de uma melhor aplicação" (C/ 2016/8600) ${ }^{10}$.

Existem outros procedimentos especiais, nomeadamente os previstos nos artigos $70 .^{\circ}$ (espaço de liberdade, segurança e justiça), $108 .{ }^{\circ}$ n. ${ }^{\circ} 2$ (ajudas de Estado) e $114 .^{\circ}$, n. $^{\circ} 9$ (mercado interno) doTFUE,os quais não possuem uma fase pré-contenciosa específica ${ }^{11}$.

A noção de incumprimento vem plasmada no artigo $258 .^{\circ}$ e traduz-se na situação em que "um Estado-Membro não cumpriu qualquer das obrigações que lhe incumbem por força dos Tratados", ou seja, "resulta da violação de qualquer norma ou princípio da ordem jurídica instituída pelos Estados membros no quadro da União Europeia"12.

\footnotetext{
8 MARTINS, Op. Cit., p. 543.

9 GORJÃO-HENRIQUES, Miguel - Direito da União - História, Direito, Cidadania, Mercado Interno e Concorrência. 9. ${ }^{a}$ ed. Coimbra: Almedina, 2009, ISBN 978-972-40-7658-4, p.487.

10 [Em linha] [Consultado em 2021-05-09], Disponível na World Wide Web: <https://ec.europa.eu/internal_market/scoreboard/performance_by_governance_tool/eu_pilot/index_en.htm>.

11 GORJÃO-HENRIQUES, Op. Cit., p. 459.

12 MOTA DE CAMPOS, João e MOTA DE CAMPOS, João Luís - Manual de direito Europeu - O sistema institucional, a ordem jurídica e o ordenamento económico da União Europeia, 6. ${ }^{a}$ ed., Coimbra: Coimbra Editora, 2010, ISBN 978-972-32-1812-1, p. 444.
} 
O incumprimento pode ser por ação ou por omissão. Por ação pode ocorrer nos casos de:

“a) adopção na ordem interna de um acto jurídico (legislativo ou infralegislativo, de carácter geral ou individual) contrário às regras da União Europeia;

b) comportamento do Estado traduzido em acções materiais, actuações administrativas ou práticas internas, seja qual for a sua natureza, violadoras da legalidade da União.

O incumprimento por omissão verifica-se quando haja:

a) recusa expressa ou tácita de adoptar na ordem interna as medidas jurídicas ou de praticar as ações materiais prescritas pelas disposições do direito da União ou impostas pelas Instituições no exercício da sua competência;

b) recusa tácita ou expressa de revogar formalmente uma norma interna que se revele incompatível com a regulamentação na União Europeia"13.

A ação por incumprimento é constituída por duas fases - a administrativa ou pré-contenciosa - que decorre perante a Comissão e a judicial - que decorre no Tribunal de Justiça, que funciona como jurisdição internacional.

É a Comissão que possui legitimidade para desencadear o processo, ao abrigo do artigo 258. ${ }^{\circ}$, ou os Estados membros, ao abrigo do artigo 259. e nesta situação, só após a Comissão ter sido chamada a estabelecer um diálogo prévio com o Estado suspeito de ser infrator - §§ 2 e 3 do artigo $259 .^{\circ}$.

A fase administrativa ou pré-contenciosa quando desencadeada pela Comissão (por ter detetado uma situação de incumprimento pelo Estado membro ou por ter existido uma denúncia de um particular ou de outro estado membro) é descrita no primeiro parágrafo do artigo $258 .^{\circ}$, iniciando-se com a formulação de um parecer fundamentado sobre o assunto, após se ter dado ao Estado oportunidade de apresentar as suas observações.

O Estado em causa receberá uma notificação por incumprimento, que a doutrina é de opinião que reveste a natureza de uma nota de culpa ${ }^{14}$, na sequência da qual o Estado deve apresentar as suas observações.

Se a Comissão não achar aquelas suficientes, formulará um parecer fundamentado, no qual pedirá um cumprimento do mesmo, dentro do prazo por si fixado. "Se o Estado em causa não proceder em conformidade com este parecer no prazo fixado pela Comissão, esta pode recorrer ao Tribunal de Justiça da União Europeia, de acordo com o $\S 2$ do Artigo $258 .^{\circ}$. Assim, relativamente à data de referência para apreciar a existência de um incumprimento nos termos do artigo $258 .^{\circ}$ é o momento em que termina o prazo fixado no parecer fundamentado.

13 Ibidem, p. 445.

14 Nesse sentido GORJÃO-HENRIQUES, Op. Cit., p. 461 e MOTA DE CAMPOS, Op. Cit., p. 453. 
Estamos perante uma faculdade da Comissão que se traduz "no exercício de um poder discricionário, não sindicável jurisdicionalmente por parte dos particulares queixosos (ou por qualquer outro ente), nem sujeito a qualquer prazo prescricional" ${ }^{15}$.

Entendendo a Comissão dar início à fase judicial, com a instauração de um processo, este encontra-se regulado no Regulamento de Processo do Tribunal de Justiça e tramita como processo comum: apresentação de petição inicial, contestação ou resposta, possíveis réplica e tréplica, possível fase instrutória, relatório preliminar (para a audiência) elaborado pelo juiz-relator do processo, audiência de julgamento com produção de alegações orais, conclusões do advogado-geral e acórdão do Tribunal.

Há dois aspetos que merecem ser referidos e que envolvem em primeiro lugar, a identidade entre a fase pré-contenciosa e a fase contenciosa, e em segundo, o ónus da prova neste tipo de ações.

Relativamente ao primeiro, é jurisprudência assente do Tribunal de Justiça que neste tipo de ações a petição da Comissão Europeia não delimita o objeto da ação, mas, sim, os documentos que esta enviou ao Estado na fase pré-contenciosa ${ }^{16}$.

Quanto ao segundo aspeto, o ónus da prova do incumprimento do Direito da União Europeia por parte do Estado alvo da mesma, cabe à Comissão Europeia, conforme jurisprudência do Tribunal de Justiça ${ }^{17}$.

No termo do processo, o Tribunal exercendo uma função de plena jurisdição decidirá da existência ou não do imputado incumprimento estadual, apreciando as normas nacionais aplicáveis para determinar se houve ou não uma violação de uma obrigação que o Estado membro assumiu. Desse modo, o Tribunal tanto pode considerar o pedido da Comissão ou do Estado procedente condenando o Estado membro, como absolvê-lo.

Nos termos do artigo 260. ${ }^{\circ}$, n. ${ }^{\circ}$ "Se o Tribunal de Justiça da União Europeia declarar verificado que um Estado-Membro não cumpriu qualquer das obrigações que the incumbem por força dos Tratados, esse Estado deve tomar as medidas necessárias à execução do acórdão do Tribunal "e se não o fizer o n. ${ }^{\circ} 2$ dispõe que "Se a Comissão considerar que o Estado-Membro em causa não tomou as medidas necessárias à execução do acórdão do Tribunal, pode submeter o caso a esse Tribunal, após ter dado a esse Estado a possibilidade de apresentar as suas observações. A Comissão

15 GORJÃO-HENRIQUES, Op. cit., pp. 460-461.

16 Acórdão Comissão c. Países Baixos de 24.6.2004, proc. C-350/02, [Em linha], [consultado 2021-05-09] Disponível na World Wide Web: <https://curia.europa.eu/juris/documents.jsf?oqp=\&for=\&mat=or \& lgrec $=\mathrm{fr} \& \mathrm{jge}=\& \mathrm{td}=\% 3 \mathrm{BALL} \& \mathrm{jur}=\mathrm{C} \&$ num $=\mathrm{C}-350 \% 252 \mathrm{F02} \&$ page $=1 \&$ dates $=\& \mathrm{pcs}=0$ or $\& \mathrm{lg}=\& \mathrm{pro}=\&$ nat $=$ or \&cit=none\%252CC\%252CCJ252CR\%252C2008E\%252C\%252C\%252C\%252C\%252C\%252C\%252C\% 252C\%252C\%252Ctrue\%252Cfalse\%252Cfalse \&language=en \&avg=\&cid=1142067>.

17 Acórdão Comissão c. Países Baixos, de 12.09.2000, proc.408/97, [Em linha], [Consultado em 2021-05-09]. Disponível na World Wide Web: <https://eur-lex.europa.eu/legal-content/EN/ TXT/?uri=CELEX\%3A61997CJ0408>. 
indica o montante da quantia fixa ou da sanção pecuniária compulsória, a pagar pelo Estado-Membro, que considerar adequado às circunstâncias."

Relativamente aos particulares lesados pelo incumprimento por um Estado membro das obrigações que the incumbem, caso a Comissão não corresponda às suas solicitações, apenas poderão agir a nível interno - por meio de uma ação de indemnização pelos prejuízos sofridos - demandando o Estado junto dos tribunais nacionais competentes, pela violação por ação ou omissão de uma norma da União Europeia, que por ser diretamente aplicável, produz o efeito imediato do reconhecimento de um direito que cabe aqueles salvaguardar. Se, entretanto, o incumprimento tiver sido declarado pelo Tribunal de Justiça a sua posição sairá ainda mais reforçada.

O Tribunal de Justiça em sede de ações de incumprimento tem vindo com a sua jurisprudência a impor-se ao poder executivo, legislativo e aos tribunais em geral, uma vez que as autoridades nacionais ficam obrigadas a não aplicar mais as normas internas e a eliminar os comportamentos nacionais considerados incompatíveis com o direito da União Europeia.

Como exemplo, ao nível do direito fiscal em que um Estado membro foi alvo de um procedimento de infração temos a seguinte situação: «[E]m janeiro de 2019 a Comissão Europeia decidiu dar início a um "procedimento de infração contra Portugal por este Estado-Membro não ter em conta a componente ambiental do imposto de matrícula aplicável aos veículos usados importados de outros Estados-Membros para fins de depreciação. A Comissão considera que a legislação portuguesa não é compatível com o artigo $110 .^{\circ}$ do TFUE, na medida em que os veículos usados importados de outros Estados-Membros são sujeitos a uma carga tributária superior em comparação com os veículos usados adquiridos no mercado português, uma vez que a sua depreciação não é plenamente tida em conta." ${ }^{18}$. Assim, a Comissão Europeia solicitou às autoridades portuguesas esclarecimentos sobre a compatibilidade das normas previstas na legislação portuguesa relativamente ao cálculo da componente ambiental do ISV aplicável aos veículos usados adquiridos noutros Estados Membros, constantes do artigo $11 .^{\circ}$ do Código do ISV, com o princípio da livre circulação de mercadorias previsto no artigo $110 .^{\circ}$ do Tratado de Funcionamento União Europeia (TFUE) ${ }^{19}$. Atualmente, a questão avançou para a fase contenciosa, estando a decorrer junto do TJUE. Paralelamente, diga-se que esta questão também originou reenvio prejudicial por parte do Tribunal Constitucional - cf. acórdão do Tribunal Constitucional n. ${ }^{\circ}$ 711/2020, de 9 de dezembro de 2020.

18 Pacote de procedimentos de infração de janeiro: principais decisões [Em linha] [consultado em 2021-05-09]. Disponível na World Wide Web: < https://ec.europa.eu/commission/presscorner/detail/pt/ MEMO_19_462>.

19 CARVALHO, Ana Sofia - Imposto sobre Veículos e Direito da União Europeia, "Cadernos de Justiça Tributária", Braga, 2020, n. ${ }^{\circ}$ 27, p. 10. 


\section{Breves conclusões}

O TJUE tem por missão pugnar pela interpretação e aplicação uniforme do Direito da União pelos Estados-membros e velar pelo seu cumprimento.

No âmbito dessas funções, ressaltam dois tipos de ações: o reenvio prejudicial e a ação por incumprimento, que desempenharam e desempenham um papel fundamental no desenvolvimento do Direito da União, contribuindo para a sua evolução, e constituem uma esperança de aplicação correta do Direito da União para os particulares.

Em particular, o reenvio é um instrumento de cooperação judiciária pelo qual os tribunais nacionais e o TJUE são chamados a contribuir para uma decisão que assegure a aplicação uniforme do direito da União Europeia no seio dos Estados-Membros, demostrando o importante papel dos tribunais num mundo globalizado, de modo a permitir uma correta aplicação do Direito num espaço geográfico para além das fronteiras nacionais. 